\section{Spina bifida trials}

SIR - I have now been referred to twice in Nature in relation to the proposed Medical Research Council (MRC) spina bifida trial, once as a representative of the National Childbirth Trust, which I am not, and once as opposed to the trial on the basis of press cuttings. One report, in Hospital Doctor, was grossly in error, but I have failed to obtain a retraction. There is a need for a controlled trial if the uncontrolled trials of Smithells and others can be sufficiently faulted. As yet, I do not consider any sufficient criticism has been made. Perhaps, with so much misunderstanding and inaccurate reporting around, I could advance what I believe to be factual comments.

(1) The MRC trial, as proposed, involves tenfold the dose of folic acid used by Smithells and his collaborators. It is in no way a supplementation trial, and, even if successful, could hardly be a basis for population exposure to such high levels.

(2) If, as critics of uncontrolled trials claim, women who take pills obediently and conceive punctually are, by nature or nurture, at low risk for recurrence, the trial, which will necessarily involve such women, would only be expected to yield some 20 cases or so, divided into four treatment groups, in 2,000 women.

(3)A trial based on randomization and null hypotheses must have a pre-set stopping rule, which may be sequential (as in tennis), or by time (as in football), or on total score (as in darts). This must be explicit before any trial starts.

(4) It is very difficult for anyone who wishes to help by giving informed consent, or by advising their patients whether they should do so, or by advising their members whether they should do so, or by advising as members of ethical committees, to find any clear criticism of the uncontrolled studies, or any clear summary of the controlled trial. The recent book (Prevention of Spina Bifida and other Neural Tube Defects, ed. J. Dobbing, Academic, London, 1983) is hardly a summary. Until matters are clearer I do not see how informed consent is possible. Has anyone given it?

(5) The Society for the Protection of the Unborn Child can hardly be criticized for drawing attention to the first trial to be based on the assumption that death before birth is preferable to disability after birth. The society may, like Greenpeace, use provocative methods, and attempt to form opinions without relevant experience on tertiary data. Their minority views are defined by their membership and should hardly occasion surprise.

The matter is difficult, and getting more so with the accumulation of much consistent data on the prevention of the relatively rare second cases. Without reference to the wisdom of the MRC trial, on which neither advance nor retreat seems possible, there is an urgent need to explore true supplementation on sections of the population, and no reason why this should depend on the
MRC trial on recurrence.

In medicine there is room both for calculation based on ignorance and for judgement based on knowledge. It would be unfortunate if these essential but error-prone partners in the conquest of disease should be seen as opposed, or if committees expert in the execution of controlled trials should become judges of whether they should be executed.

Department of Biochemistry,

University of Oxford,

Oxford $O X 13 Q U, U K$

\section{Biotech patent}

SIR - I read with interest the article concerning the petition filed by Harold $\mathrm{C}$. Wegner of this firm for access to the file in the US Patent Office of the pending "Cohen/ Boyer" product application (Nature 25 August, p.674). Generally speaking, the article was fair to me and the firm. However, we strongly object to the comment of $\mathrm{Mr}$ Bertram Rowland, Stanford University's attorney, as quoted by you, that the petition was filed out of "crass commercialism".

Wegner \& Bretschneider filed this petition at the request of a client, totally without relation to the publication of an analysis of the Cohen/Boyer case. The "book" mentioned by Mr Rowland in the article was to be nothing more than a written exposition of materials orally presented to me in Zurich in March 1981, updated to December 1982.

Petitions for access, by the way, are not uncommon; we have filed many. If this petition be "novel", the novelty stems from the unprecedented attempt of Stanford to conceal from public view a file already made public by Stanford's own act.

We cannot believe that Stanford would stand behind Mr Rowland's false statement or that Stanford would have approved it had it had prior knowledge of what $\mathrm{Mr}$ Rowland was going to say about us.

BARRY E. BRETSCHNEIDER

Wegner \& Bretschneider,

2030 M Street, N. W.,

Washington, D.C. 20036, USA

\section{No to drugs}

SIR - I write only with great trepidation after suffering 57 years observing the treatment of a great number of schizophrenic patients and after treating many of them not with drugs but with a particular method of dynamic psychotherapy. My reasons are as follows:

(1) I have just returned from the World Congress of Psychiatrists. There were hundreds of papers and discussions on the great value and success of so-called "modern drugs", especially for patients carrying the label "schizophrenia".

(2) There were no discussions or papers read, as far as I was able to establish, on the side effects, shortcomings and damage caused by these drugs.

(3) In the plenary sessions on the five mornings, not one paper was read on the psychotherapy of schizophrenic patients.

Some of the psychiatrists attending this congress treat their patients whom they have diagnosed as schizophrenic with 18 tablets of the so-called tranquillizers every day. This makes the patients sleep for 16 to 20 hours a day and they are told they will have to do this for the rest of their lives. At the same time the psychiatrist who is being very kind to them leads them to believe that he is "saving their lives".

I treated only one of these patients. When I asked him the second time I saw him to take 17 instead of 18 tablets which he was used to taking, he was very upset and shouted "no, no, no"' as if God himself had ordered the 18 tablets. It shows the degree of faith the patient had in the psychiatrist. However, after one month of intensive dynamic psychotherapy, the patient threw all his drugs out of the window, started to work and became a "human being" not a "chronic schizophrenic". For the past year he has been in charge of a very busy business where he has to meet hundreds of people every day.

I hope that these remarks will not be interpreted as any criticism of the drugs firms or drug industry. Any drug which is able to relieve suffering is of service to humanity. There is no doubt that the socalled tranquillizers, for example, have been a great help, especially to those people such as nurses and relatives who have to care for mental patients.

It is still generally accepted by the psychiatric profession that we do not know what schizophrenia is. Any research to try to discover the answer to this condition is justified. What is not justified is to presume that schizophrenia exists as a pathological entity, when this has not been scientifically proven. What is of the greatest importance for the psychiatric profession and the drug industry is:

(1) To dissociate themselves from those who exaggerate the value of drugs.

(2) Not to make false promises to patients and relatives.

(3) To consider the side effects, shortcomings and sometimes damage which some drugs can produce if given in quantity.

(4) Most important of all, they must keep in sight the fact that the overuse of drugs has helped to swell the number of so-called chronic psychiatric patients. It is much easier to prescribe drugs than to try to find out why a patient has developed to the point when the label "schizophrenia" has to be given. This easy way has made many psychiatrists blind or unwilling to seek methods which would change the patient into a normal and productive human being.

I would like to urge the drugs industry to begin to work together with those psychiatrists who are developing ways of understanding causes of this so-called "schizophrenic illness". High-dose drug therapy is often not the answer.

140 Harley Street, London W1, UK 